\title{
PLASMA VOLUME CHANGES FOLLOWING THE ADMINISTRA- TION OF ALBUMIN TO PATIENTS WITH THE NEPHROTIC SYNDROME
}

\author{
BY F. P. CHINARD, ${ }^{1}$ H. D. LAUSON, ${ }^{2}$ H. A. EDER, ${ }^{2}$ AND R. L. GREIF ${ }^{2}$ \\ (From the Hospital of the Rockefeller Institute for Medical Research, New York, N. Y., and \\ the Departments of Medicine and of Physiological Chemistry, The Johns Hopkins \\ School of Medicine, Baltimore, Md.)
}

(Submitted for publication May 12, 1953; accepted December 31, 1953)

In the course of a study of patients with the nephrotic syndrome, data have been obtained on the changes of plasma volume which followed the intravenous administration of concentrated human plasma albumin. These data are presented here together with a thermodynamic formulation of the Starling hypothesis and a brief discussion of the mechanism of action of albumin.

According to the Starling hypothesis, four major factors are involved in the regulation of the net movement of water across the capillary walls which separate the plasma and interstitial fluid compartments. The factors are the hydrostatic pressures in the capillaries and in the interstitial fluid and the so-called colloid osmotic pressures of plasma and of interstitial fluid. Variations of one or more of these factors may determine a net movement of water and a change in the respective volumes of the two compartments. The problem is essentially that of membrane equilibria and of disturbances of these equilibria.

Membrane equilibria with respect to water are most simply described in terms of the chemical potential of water in each of the two compartments and in terms of the factors which affect the chemical potential of water (see, for example [1]). Let the chemical potential of water be greater in one compartment of a two compartment system than in the other compartment. Then, provided a path is available there will be net movement of water from the compartment where the chemical potential of water is higher to the compartment where the chemical potential of water is lower. The two compartments in the system under consideration are the plasma and interstitial fluid; their volumes are denoted by $V^{\prime \prime}$ and $V^{\prime}$, respectively. The difference of the

1 Present Address: The Johns Hopkins School of Medicine, Baltimore, Md.

2 Present Address : Cornell University Medical College, New York, N. Y. chemical potentials of water in the two compartments is :

$$
\begin{aligned}
& \mu^{\prime \prime}{ }_{\mathrm{H}_{2} \mathrm{O}}-\mu^{\prime}{ }_{\mathrm{H}_{2} \mathrm{O}}=\mathrm{V}_{\mathrm{H}_{2} \mathrm{O}}\left(\mathrm{P}^{\prime \prime}-\mathrm{P}^{\prime}\right)
\end{aligned}
$$

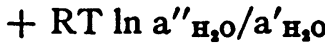

where $\mu \mathrm{H}_{2} \mathrm{O}$ is the chemical potential of water, $\overline{\mathrm{V}}_{\mathrm{H}_{2} \mathrm{O}}$ is the partial molal volume of water, $\mathrm{P}$ denotes pressure, $R$ is the gas constant, $T$ is the absolute temperature, $\ln$ denotes natural logarithm, and $\mathrm{aH}_{2} \mathrm{O}$ the activity of water. The double primes refer to the plasma compartment and the single primes to the interstitial fluid compartment. The activities of water in plasma and in interstitial fluid are expressed with respect to the activity of water in a solution which is free of protein but contains all the other constituents of plasma and interstitial fluid. ${ }^{3}$

At equilibrium $\mu^{\prime \prime} \mathrm{H}_{2} \mathrm{O}=\mu^{\prime} \mathrm{H}_{2} \mathrm{O}$; no net movement of water occurs and there is no change of $\mathrm{V}^{\prime \prime}$ or $\mathrm{V}^{\prime}$. Under this condition on rearrangement of (1) there is obtained :

$$
\text { (2) } \mathrm{P}^{\prime \prime}+\frac{\mathrm{RT}}{\overline{\mathrm{V}}_{\mathrm{H}_{2} \mathrm{O}}} \ln \mathrm{a}^{\prime \prime}{ }_{\mathrm{H}_{2} \mathrm{O}}=\mathrm{P}^{\prime}+\frac{\mathrm{RT}}{\overline{\mathrm{V}}_{\mathrm{H}_{2} \mathrm{O}}} \ln \mathrm{a}_{\mathrm{H}_{2} \mathrm{O}}
$$

The equilibrium situation is illustrated in Figure 1. The values of the pressure are indicated by the vertical lines with arrows pointing up because increase of pressure, other things being equal, results in an increase of the chemical potential of water. Increase of protein concentration, other things being equal, results in a decrease of the

${ }^{3}$ The most convenient means of determining the activities is by the use of an osmometer, the membrane of which is impermeable to proteins but permeable to all the other constituents. The effects of the unequal distribution of small ions (Gibbs-Donnan effect) in establishing further differences in the activities of water are thus included with the effects of the unequal distribution of the proteins. Because there is some confusion about the meaning of osmotic pressure $(2,3)$, use of this term has been avoided where possible. 


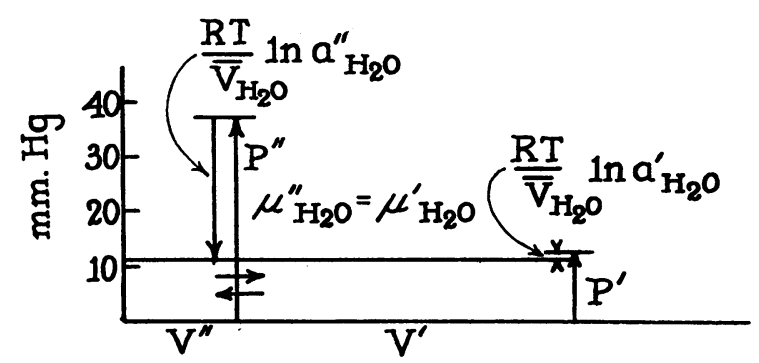

Fig. 1. Schematic Representation of the Relationship Among the Four Major Variables and the Volumes of Plasma and of Interstitial Fluid. (See Text for Details)

activity of water. Because the activity of water in plasma and in interstitial fluid is less than unity, the values of the RT terms are negative and are indicated by the lengths of the vertical lines with downward arrows. The resultant of the pressure and RT terms is indicated for each compartment by the horizontal lines at the tip of each downward arrow. The values are found on the ordinate scale in $\mathrm{mm}$. of $\mathrm{Hg}$ and are, in effect, the values of the chemical potentials of water in the particular compartments considered with respect to water in the reference standard used to define the activities.

It is evident on inspection of the diagram that there are six variables: $P^{\prime \prime}, P^{\prime}, a^{\prime \prime} \mathbf{H}_{2} \mathbf{O}, a^{\prime} \mathbf{H}_{2} \mathbf{O}, V^{\prime \prime}$, and $\mathrm{V}^{\prime}$. A change in one of the first four variables will disturb the equilibrium; as a result there will be net movement of water from one compartment to the other. This net movement will continue until the chemical potentials of water in the two compartments again become equal because of changes of the other variables occurring as the result of the net shift of water. $\mathrm{V}^{\prime \prime}$ and $\mathrm{V}^{\prime}$ may change without necessarily producing a significant change in any of the other variables. However, with marked increases of plasma volume there may be expected some increase in $\mathrm{P}^{\prime \prime}$ and similarly with marked increases of interstitial fluid volume there may be expected some increase in $\mathrm{P}^{\prime}$. Conversely, with marked decreases of $V^{\prime \prime}$ and $V^{\prime}$, there may be expected some decrease of $\mathrm{P}^{\prime \prime}$ and $\mathrm{P}^{\prime}$. Changes of red cell and suspended lipid volumes

TABLE I

Volume of distribution of T-1824 following different rates of injection

\begin{tabular}{|c|c|c|c|c|c|}
\hline \multirow[b]{2}{*}{ Patient } & \multicolumn{2}{|c|}{ First injection } & \multicolumn{2}{|c|}{ Second injection } & \multirow{2}{*}{$\begin{array}{l}\text { Difference } \\
\text { in per cent } \\
\text { of average }\end{array}$} \\
\hline & Duration & $\begin{array}{c}\text { Volume of } \\
\text { distribution }\end{array}$ & Duration & $\begin{array}{l}\text { Volume of } \\
\text { distribution }\end{array}$ & \\
\hline $\begin{array}{l}\text { O. K. } \\
\text { S. B. } \\
\text { J. K. }\end{array}$ & $\begin{array}{c}\text { seconds } \\
5 \\
5 \\
6\end{array}$ & $\begin{array}{c}m l . \\
2380 \\
3360 \\
2410\end{array}$ & $\begin{array}{c}\text { seconds } \\
165 \\
109 \\
60\end{array}$ & $\begin{array}{c}m l . \\
2400 \\
3420 \\
2380\end{array}$ & $\begin{array}{c}\% \\
0.8 \\
1.9 \\
1.3\end{array}$ \\
\hline
\end{tabular}

Volume of distribution of T-1824 following repeated injections of the dye-Comparison of the volumes of distribution of $T-1824$ injected in aqueous solution and volume of distribution of T-1824 injected bound to human plasma albumin*

\begin{tabular}{|c|c|c|c|c|c|}
\hline \multirow[b]{2}{*}{ Patient } & \multirow[b]{2}{*}{ Date } & \multicolumn{2}{|c|}{ First injection } & \multicolumn{2}{|c|}{ Second injection } \\
\hline & & $\begin{array}{c}\text { Dye } \\
\text { injected }\end{array}$ & $\begin{array}{c}\text { Volume of } \\
\text { distribution }\end{array}$ & $\begin{array}{c}\text { Dye } \\
\text { injected }\end{array}$ & $\begin{array}{c}\text { Volume of } \\
\text { distribution }\end{array}$ \\
\hline $\begin{array}{l}\text { S. B. } \\
\text { S. B. } \\
\text { S. B. } \\
\text { O. K. } \\
\text { A. G. }\end{array}$ & $\begin{array}{l}6-9-48 \\
6-16-48 \\
7-8-48 \\
7-8-48 \\
7-10-48\end{array}$ & $\begin{array}{l}m l . \\
2 \\
2 \\
1 \\
1 \dagger \\
2 \\
2\end{array}$ & $\begin{array}{c}m l . \\
2840 \\
2760 \\
2980 \\
3090 \\
2350 \\
3020\end{array}$ & $\begin{array}{c}m l . \\
2 \\
1 \\
1 \\
2 \dagger \\
1 \\
3\end{array}$ & $\begin{array}{c}m l . \\
2930 \\
2700 \\
3090 \\
2940 \\
2370 \\
3070\end{array}$ \\
\hline $\begin{array}{l}\text { O. K. } \\
\text { A. G. }\end{array}$ & & \multicolumn{2}{|c|}{ T-1824 in water } & \multicolumn{2}{|c|}{ T-1824 mixed with albumin } \\
\hline $\begin{array}{l}\text { J. R. } \\
\text { C. C. } \\
\text { R. O'F. } \\
\text { S. B. }\end{array}$ & $\begin{array}{l}10-13-48 \\
10-13-48 \\
10-13-48 \\
10-13-48\end{array}$ & & $\begin{array}{r}1260 \\
1305 \\
750 \\
3260\end{array}$ & & $\begin{array}{r}1310 \\
1335 \\
745 \\
3380\end{array}$ \\
\hline
\end{tabular}

* All volumes are calculated from plasma concentration 10 minutes after injection.

$\dagger$ Third and fourth injections, respectively. 
in blood may similarly affect $\mathrm{P}^{\prime \prime}$; tissue cell volume changes may result in small but nonetheless significant changes of $\mathrm{P}^{\prime}$.

It is evident from these relationships that no valid prediction of the changes of the plasma volume can be made from data obtained on only one of the four variables in equation (2). It has been suggested, for example, that because of the decrease in the plasma albumin concentration (resulting in an increase in $\mathrm{a}^{\prime \prime} \mathrm{H}_{2} \mathrm{O}$ ) found in patients with the nephrotic syndrome there should be a decrease in the plasma volume. Such a decrease in the plasma volume may occur if no changes occur in the values of the other variables or if the changes in these values annul each other. In other words, reduction of the plasma volume is not a necessary consequence of the reduction of the plasma albumin concentration. Validation or invalidation of the Starling hypothesis cannot be based on data on one of the four major variables and on the plasma or interstitial fluid volumes. However, the Starling hypothesis and the theory of membrane equilibria can be applied to observed changes in measurable variables as they occur in patients with cardiac edema, nephrotic edema, cirrhosis with ascites, burns, hemorrhage, anemia, starvation edema, etc. ; also, limited deductions can be made from the thermodynamic formulation and from the measurements regarding changes which may have occurred in the other variables.

\section{METHODS}

Plasma volume: The dilution volume of $\mathrm{T}-1824$ ten minutes after injection was used as a measure of the plasma volume. Because of the very rapid changes of plasma volume during the course of the experiments extrapolation from time-concentration plots was not possible. The concentration of the dye in plasma was determined by an acetone extraction procedure $(4,5)$. Repeated injections of the dye were made around-the-clock during a number of 24-hour periods; because of the high renal clearance of the dye (6) the subjects had regained their natural color within 12 to 18 hours following the last injection. As a test of the reproducibility of the calculated plasma volumes in patients with the nephrotic syndrome a few experiments were carried out on the effect of the rate of injection of the dye, of multiple injections, and of prior binding to albumin. The results are shown in Tables I and II. The differences in the results are no greater than the probable technical error. There is no evidence that the low plasma albumin concentration and the high rate of disappearance of the dye found in these patients introduces errors other than those already inherent in the procedure used.

Plasma protein concentrations: Albumin and total globu-

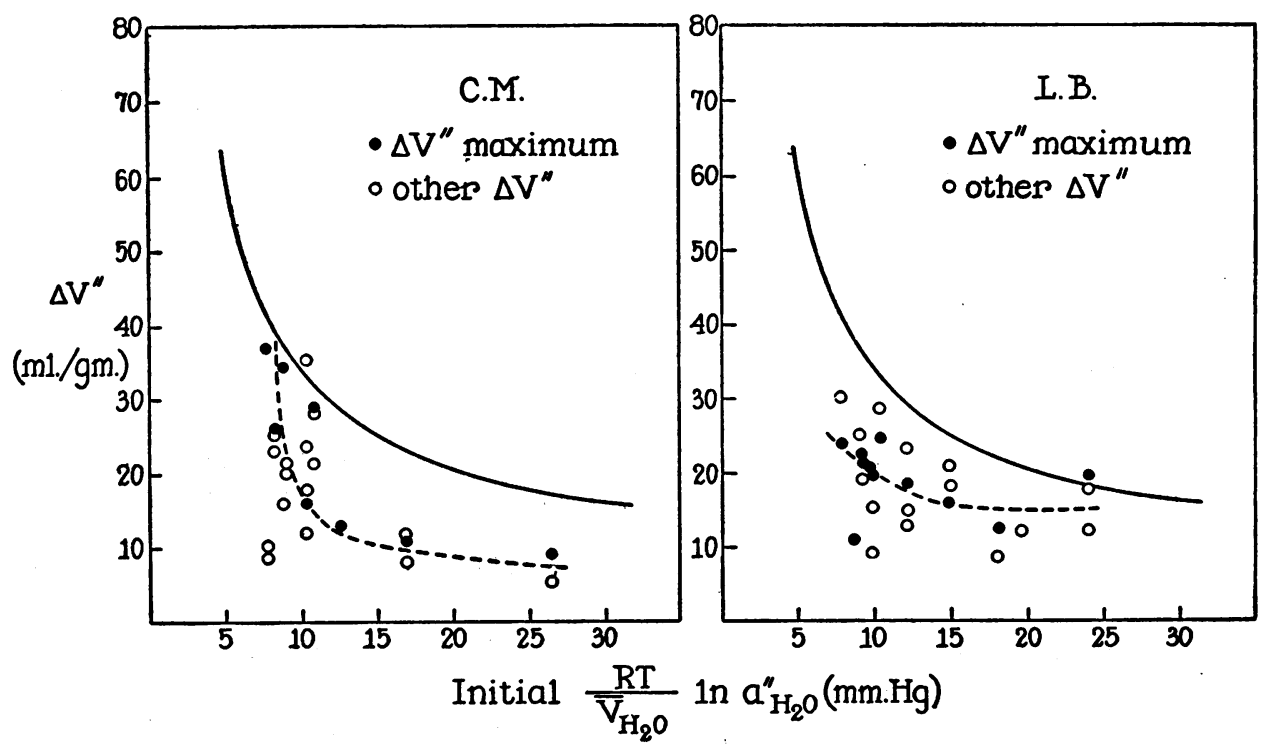

Fig. 2. Relationship of the Increase in V" per Gram of Albumin Retained in the Plasma ( $\Delta V^{\prime \prime}$, Ml. per GM.) to the Initial Value of the RT Term (i.e., in the Morning Before the Albumin Was Administered)

The values on the abscissa have a negative sign. The continuous line is that relationship which would have obtained in the event of a maximal "iso-osmotic" response. See Tables III and IV. 
TABLE III

Data on L. B.*

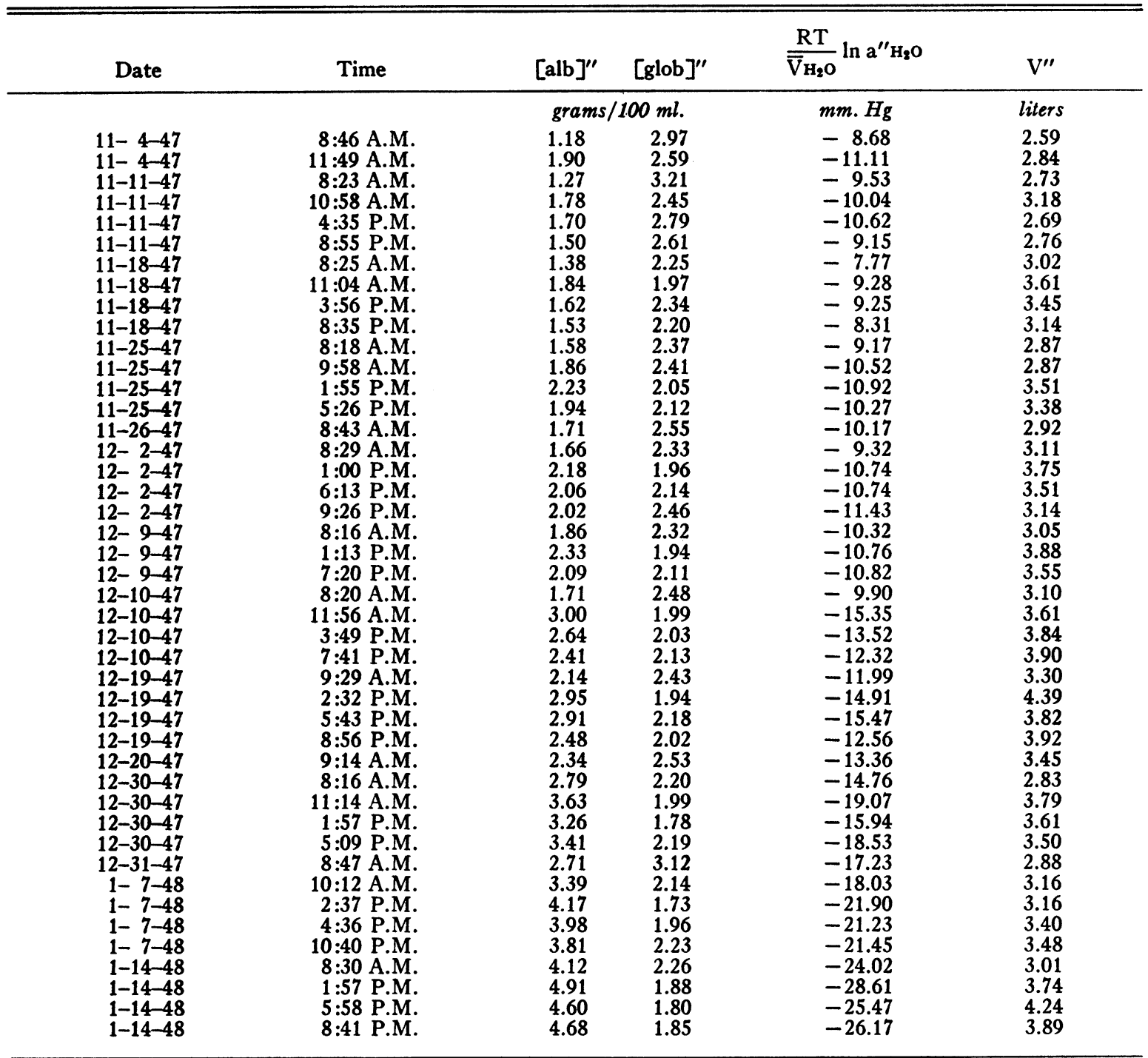

*The concentrations of albumin and globulin in plasma are denoted by [alb]" and [glob]", respectively.

lin concentrations were determined by a modification (7) of Howe's procedure.

Calculation of the value of the RT term: The corrected expression of Scatchard, Batchelder, and Brown $(8,9)$ cited by Pappenheimer and Soto-Rivera (10) was used:

$$
\pi=\frac{268(1-0.64 \mathrm{~g}) \mathrm{c}}{[1-(0.4+0.9 \mathrm{pH}) \mathrm{c}]}
$$

$\pi$ is the "colloid osmotic pressure" and is equal to the RT term, $\mathrm{c}$ is the total protein concentration in $\mathrm{Gm}$. per $\mathrm{ml} ., \mathrm{g}$ is the ratio of the globulin concentration to the total protein concentration; $\mathrm{pH}$ is assumed to be constant at a value of 7.35. Scatchard (9) has pointed out the limited applicability of the above expression; our data do not meet the criteria of the more accurate expressions (11, 12). The RT term is expressed in $\mathrm{mm}$. $\mathrm{Hg}$.

Albumin: This was administered either as a 25 per cent solution or, diluted with 5 per cent glucose, as a 10 per cent solution over a period of 30 to 90 minutes.

\section{RESULTS}

Change in plasma volume following the administration of albumin

Around-the-clock studies of the plasma volume and of the albumin and globulin concentrations in plasma were carried out in two patients during 
courses of albumin therapy. Patient C. M. was a 19-year old girl who recovered completely ; patient L. B. was a 19-year old male who later died in uremia. The increase of plasma volume per gram of albumin retained in the circulation is shown in Figure 2 in relation to the value of the RT term before the day's albumin was administered (see Tables III and IV for data). The continuous line represents the relationship which would have obtained had there been no change in the value of the $\mathrm{RT}$ term following the administration of albumin, i.e., had the response been "iso-osmotic." All but one of the points fall below the "iso-osmotic" line. Less extensive studies were carried out in other patients; the results were similar.

\section{DISCUSSION}

Scatchard, Batchelder, and Brown (8) have suggested that there are two possible but opposite maximal responses to the administration of albumin. The plasma volume may increase to such an extent that the value of the RT term for plasma remains constant; alternatively, the plasma volume may remain grossly unchanged and the value of the RT term increases. Armstrong (13) has termed the first response "iso-osmotic" and the second "iso-metric."

Inspection of Figure 2 shows that in both patients the response was intermediate; less extensive data in other patients show a similar intermediate

TABLE IV

Data on C. $M$.

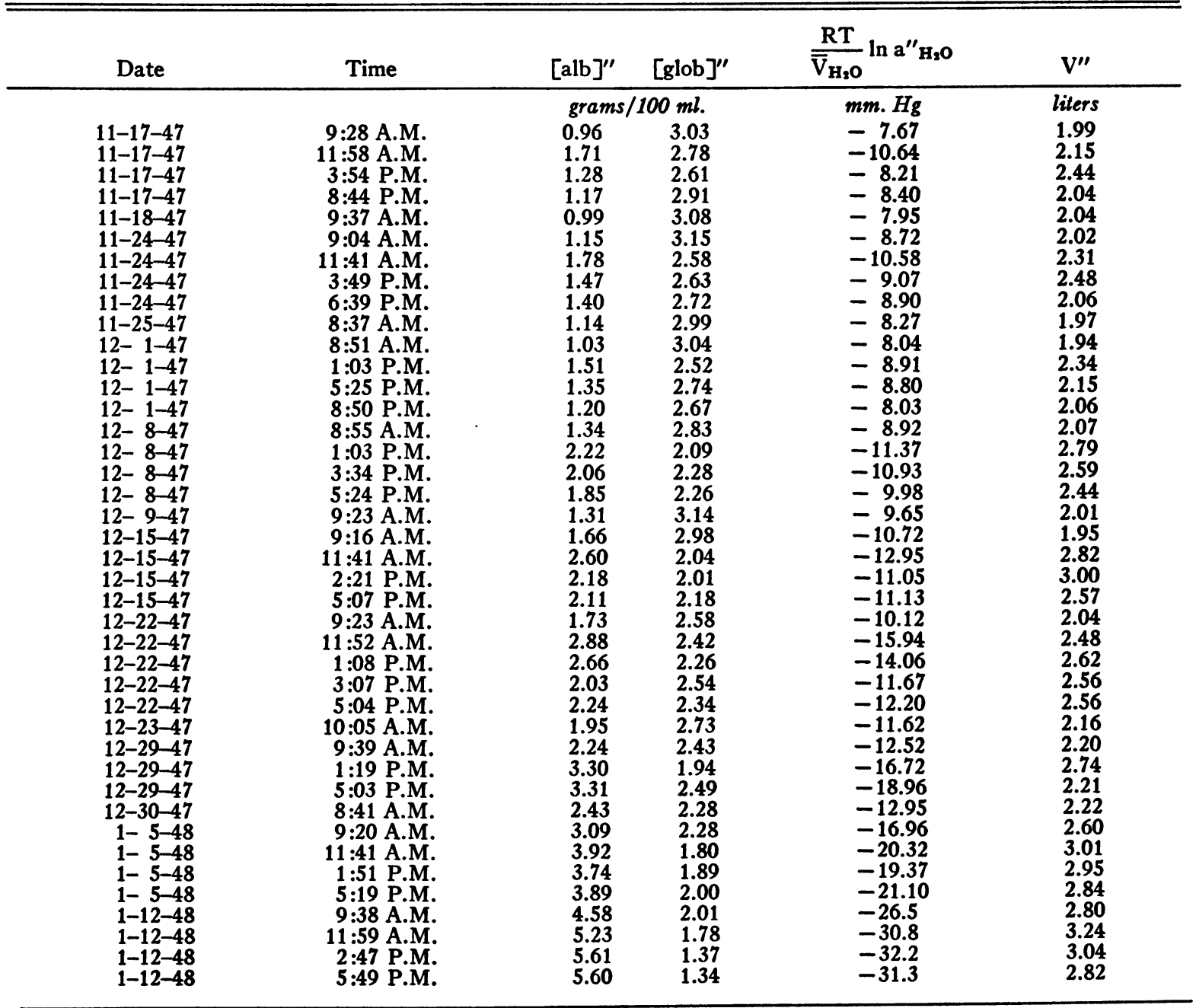


response. The "iso-metric" response may be taken to imply that $\mathrm{P}^{\prime \prime}$ increases; the "iso-osmotic" response may be taken to imply that $\mathrm{P}^{\prime \prime}$ does not change. The intermediate response found in these studies suggests that an increase in $\mathrm{P}^{\prime \prime}$ did occur. Direct evidence is not available. However, venous pressure measurements in occasional aroundthe-clock studies in these and other patients showed increases, at the time of maximum plasma volume, of the order of 1 to $3 \mathrm{~mm}$. $\mathrm{Hg}$ in most cases; increases as great as $8 \mathrm{~mm}$. $\mathrm{Hg}$ occurred in patients in whom signs of overloading of the circulation were present.

Changes may also have occurred in the other variables, i.e., $\mathrm{P}^{\prime}$, the interstitial fluid pressure, and $\mathbf{a}^{\prime} \mathrm{H}_{2} \mathrm{O}$, the activity of water in the interstitial fluid. It is known that the concentration of albumin in ascitic fluid increases when albumin is administered intravenously. The increase is roughly proportional to the increase in plasma albumin concentration; $\mathrm{a}^{\prime} \mathrm{H}_{2} \mathrm{O}$ must decrease. (Because the concentration of albumin in ascitic fluid remains small compared to the concentration of albumin in plasma, variations of $\mathrm{a}^{\prime} \mathbf{H}_{\mathbf{2}} \mathrm{O}$ may not be of major significance. No information is available on the variations of the albumin concentration in interstitial fluid immediately following the intravenous administration of albumin.) In addition, large shifts of water from interstitial fluid may, as indicated above, be accompanied by a reduction of $\mathrm{P}^{\prime}$. As shown in Tables III and IV, the changes of the RT term for water in plasma are of the order of 2 to $6 \mathrm{~mm}$. $\mathrm{Hg}$; changes of $\mathrm{P}^{\prime \prime}$, on the basis of the venous pressure changes, probably do not exceed 3 $\mathrm{mm}$. $\mathrm{Hg}$ in most instances. From this it may be deduced that the changes of $\mathrm{P}^{\prime}$ probably did not exceed $3 \mathrm{~mm}$. $\mathrm{Hg}$ in spite of net shifts of water approaching 1 liter.

On the basis of the data and of the relationships implied in Figure 1 and in equation (2) it may be expected that the response to the administration of albumin will not generally be "iso-osmotic." The response may be moderated not only by increases in $\mathrm{P}^{\prime \prime}$, but also by decreases in $\mathrm{P}^{\prime}$ and in $\mathrm{a}^{\prime} \mathrm{H}_{2} \mathrm{O}$. As a matter of point, the "iso-osmotic" response is not necessarily a maximal response. Circulatory adjustments can occur quite rapidly; these could result in a decrease in $\mathrm{P}^{\prime \prime}$ even with an expanded blood volume. Under such circumstances a greater increase of plasma volume could occur than would be predicted on the basis of an "iso-osmotic" response.

The mechanism of action of albumin (and of such substances as Dextran and polyvinylpyrrolidone) in effecting a net shift of water from interstitial fluid to plasma can be described most simply as follows. Assume that the chemical potentials of water in plasma, $\mu^{\prime \prime} \mathrm{H}_{2} \mathrm{O}$, and interstitial fluid, $\mu^{\prime} \mathrm{H}_{2} \mathrm{O}$, are initially equal. Administration of albumin intravenously results in a decrease of $a^{\prime \prime} \mathrm{H}_{2} \mathrm{O}$ and hence of $\mu^{\prime \prime} \mathrm{H}_{2} \mathrm{O}$. A net movement of water occurs from interstitial fluid to plasma until $\mu^{\prime \prime} \mathrm{H}_{2} \mathrm{O}$ and $\mu^{\prime} \mathrm{H}_{2} \mathrm{O}$ are again equal as a result of the changes in all four variables attendant on the redistribution of water.

Because of the complex nature of the relationships no exact prediction can be made of the events to be expected following a natural or induced change in one or more of the six variables, $\mathrm{P}^{\prime \prime}, \mathrm{P}^{\prime}$, $a^{\prime \prime} \mathrm{H}_{2} \mathrm{O}, \mathrm{a}^{\prime} \mathrm{H}_{2} \mathrm{O}, \mathrm{V}^{\prime \prime}$, and $\mathrm{V}^{\prime}$. At best, measurements can be made of some of the variables, the theory of membrane equilibria applied, and deductions made as to the changes of the remaining variables. Finally, it may be pointed out that changes in capillary surface area may have an effect on the rate at which net shifts of water take place but will not necessarily affect directly the final distribution of water when equilibrium is reached.

\section{SUMMARY}

The changes in plasma volume following the intravenous administration of human plasma albumin have been estimated over a number of $24-$ hour periods in two patients with the nephrotic syndrome. The change of plasma volume per gram of albumin retained in the circulation is, in nearly all instances, less than would have obtained had the response been "iso-osmotic." The results suggest that an increase in capillary hydrostatic pressure prevented the maximal "iso-osmotic" response. On the basis of the theory of membrane equilibria, it is pointed out that changes in the other variables may also have occurred; the value of the estimated decrease of interstitial fluid pressure is of the order of 1 to $3 \mathrm{~mm}$. $\mathrm{Hg}$ for net shifts of water approaching 1 liter. The mechanism of action of albumin is briefly discussed in terms of the theory of membrane equilibria. 


\section{REFERENCES}

1. Adair, G. J., The theory of membrane equilibrium. Trans. Faraday Soc., 1937, 33, 1106.

2. Clark, W. M., Topics in Physical Chemistry, ed. 2, Baltimore, Williams \& Wilkins, 1952.

3. Chinard, F. P., The definition of osmotic pressure. J. Chem. Ed., 1954, 31, 66.

4. Chinard, F. P., and Eder, H. A., The determination of the concentration of the dye T-1824 in normal and lipemic plasmas. J. Exper. Med., 1948, 87, 473.

5. Chinard, F. P., Estimation of plasma volume by dye dilution method in Methods in Medical Research, M. B. Visscher, ed., vol. 4, Chicago, The Year Book Publishers, 1951, p. 38.

6. Chinard, F. P., Lauson, H. D., and Eder, H. A., Relationship of the renal clearances of T-1824 and atbumin in some patients with proteinuria. J. Clin. Invest., 1952, 31, 895.

7. Kingsley, G. R., A rapid method for the separation of serum albumin and globulin. J. Biol. Chem., 1940, 133, 731.
8. Scatchard, G., Batchelder, A. C., and Brown, A., Chemical, clinical, and immunological studies on products of human plasma fractionation. VI. Osmotic pressure of plasma and of serum albumin. J. Clin. Invest., 1944, 23, 458.

9. Scatchard, G., The colloid osmotic pressure of serum. Science, 1951, 113, 201.

10. Pappenheimer, J. R., and Soto-Rivera, A., Effective osmotic pressure of the plasma proteins and other quantities associated with the capillary circulation in the hindlimbs of cats and dogs. Am. J. Physiol., 1948, 152, 471.

11. Scatchard, G., Physical chemistry of protein solutions. I. Derivation of the equations for osmotic pressure. J. Am. Chem. Soc., 1946, 68, 2315.

12. Scatchard, G., Batchelder, A. C., and Brown, A., Preparation and properties of serum and plasma proteins. VI. Osmotic equilibria in solutions of serum albumin and sodium chloride. J. Am. Chem. Soc., 1946, 68, 2320.

13. Armstrong, S. H., Jr., Mechanisms of action of serum albumin therapy in internal medicine. Am. J. Med., 1948, 4, 390. 